\title{
An Exploratory Study of Cognitive Functioning and Psychological Well-Being in Middle-Aged Adults with Diabetes Mellitus
}

\author{
Susmita Halder ${ }^{1}$ Shinjini Samajdar ${ }^{1} \quad$ Akash Kumar Mahato $^{1}$ \\ ${ }^{1}$ Department of Clinical Psychology, Amity University, Kolkata, \\ West Bengal, India \\ Address for correspondence Susmita Halder, PhD, Department of \\ Clinical Psychology, Amity University, Major Arterial Road, Action \\ Area II, Rajarhat, New Town, Kolkata, West Bengal 700135, India \\ (e-mail: shalder@kol.amity.edu).
}

J Soc Health Diab:2020;8:8-12

\begin{abstract}
Background Diabetes mellitus is a chronic metabolic disorder characterized by increased level of blood sugar for a prolonged period of time. Apart from its impact on the bodily functions, the disorder has its own psychological consequences, commonly in terms of stress reaction, anxiety, and depression. Diabetes is also known to affect cognitive functions, but it is less studied in the Indian population and relatively ignored in the management plan. Discerning the cognitive functions in middle-aged adults diagnosed with diabetes can give valuable insight into comprehensive management of the disorder. With this background, the study attempted to explore the cognitive functioning and psychological well-being of middle-aged adults with diabetes and compared with healthy individuals.

Methods A total of 30 middle-aged adults of both sexes diagnosed with diabetes type 2 were undertaken for the study and compared with 30 healthy adults regarding measures of cognitive functioning and psychological well-being. The measures were also explored for relationship if any with illness duration.

Results Middle-aged adults with diabetes differed significantly in terms of response inhibition and processing speed compared with healthy controls. The groups significantly

Keywords

- diabetes

- middle-aged adults

- cognitive functioning

- well-being differed on subjective Psychological well-being in terms of self-control, anxiety and depression, and vitality. Duration of illness was found to be related to anxiety symptoms. Conclusion Diabetes affects response inhibition and processing speed in middle-aged adults. Assessing and addressing impairment in cognitive functions is recommended for a comprehensive management of diabetes in middle-aged adults.
\end{abstract}

\section{Introduction}

Diabetes is a chronic disease that occurs when the pancreas is no longer able to make insulin or when the body cannot make good use of the insulin it produces. Over the long term, the effects of diabetes mellitus include long-term harm, dysfunction, damage, and failure of various organs and tissues. ${ }^{1}$

The impact of diabetes is not only on body organs, rather it also affects psychological health. Stress reaction could be easily the most common psychological sequel upon diagnosis of diabetes. However, in long term, the psychological consequences may manifest in terms of anxiety and or depression. Anticipation of hypoglycemia is also a common concern., ${ }^{2,3}$ Also, the fear related to self-care behavior related to diabetes could enhance the anxiety in the patients. ${ }^{4}$ Comorbid conditions such as mental health disorders and diabetes are linked with each other. Thomas Willis proposed the connection between the affective symptoms and diabetes and how

(c) 2020. Novo Nordisk Education Foundation.

This is an open access article published by Thieme under the terms of the Creative Commons Attribution-NonDerivative-NonCommercial-License, permitting copying and reproduction so long as the original work is given appropriate credit. Contents may not be used for commercial purposes, or adapted, remixed, transformed or built upon. (https://creativecommons.org/licenses/by-nc-nd/4.0/) Thieme Medical and Scientific Publishers Pvt. Ltd., A-12, 2nd Floor, Sector 2, Noida-201301 UP, India 
it is important to manage psychiatric conditions in patients with diabetes. ${ }^{5}$ Short- and long-term complications of psychiatric conditions negatively affect the treatment adherence in diabetes.

Patients with diabetes mellitus have shown mild-tomoderate level of deficits in different cognitive domains of varied degrees, specifically visuospatial abilities, motor speed, attention, and psychomotor abilities, compared with nondiabetic individuals. ${ }^{6-9}$ Type 2 diabetes has also been associated with decreases in executive function, verbal memory, complex motor functioning, working memory immediate recall, delayed recall, verbal fluency, visual retention, and attention. ${ }^{10-12}$ It has been found that the prevalence of cognitive dysfunction is more in nontreated patients of diabetes than treated patients. Several studies suggest that cognitive dysfunction in diabetes is more prominent when the total duration of diabetes is 5 or more years. Studies suggest that long-term or chronic diabetes mostly impacts recent memory, attention, and concentration, as compared with the control group. ${ }^{13-15}$

However, there are many contrasting studies in the literature in this domain and few are from India. The middle-aged population, especially those above 50 years of age, is already at risk of age-appropriate cognitive decline. ${ }^{16}$ Identification of cognitive domains affected due to diabetes would help in formulating a better diagnosis and intervention plan. With this background, this study explored and compared the cognitive functioning and psychological well-being of middle-aged adults with diabetes with healthy controls. The relationship between duration of illness, cognitive functions, and psychological well-being of the patients was also explored.

\section{Methods}

\section{Participants and Procedure}

Purposive sampling was used for this study to explore cognitive functioning and psychological well-being in middle-aged adults with diabetes. The total sample consisted of 60 middle-aged adults of both sexes (including 30 diagnosed with diabetes and 30 healthy controls). Inclusion criteria for the patients with diabetes $(n=30)$ were as follows: (1) within the age range of 40 to 60 years, (2) diagnosed with diabetes type 2, (3) a minimum duration of 5 years or more after diagnosis, and (4) minimum education level of eighth grade. Patients with a history of major psychiatric illness or mood disorders prior to diagnosis of diabetes, any other major medical illness, or neurologic disorder were excluded from the sample.

Inclusion criteria for the healthy controls $(n=30)$ were as follows: (1) healthy individuals of both sexes within the age range of 40 to 60 years and (2) minimum education level of eighth grade. Any patient with a history of psychiatric, medical, or neurologic disorders was excluded.

Data were collected from the outpatient department of specialty clinics and residential areas of Kolkata. Informed consent was taken from participants.

\section{Measures}

Semistructured sociodemographic and clinical data sheet was used to obtain details regarding age, sex, education level, occupation, and duration of illness.

Cognitive functions and psychological well-being of the sample was assessed using the following tools:

- Verbal Working Memory N Back Test: this 1 back and 2 back versions of Verbal Memory $\mathrm{N}$ back test was used to assess verbal working memory of the sample. The verbal $1 \mathrm{~N}$ back test requires verbal storage and rehearsal, whereas the $2 \mathrm{~N}$ back version requires manipulation of information. The Indian norms ${ }^{17}$ for the test were used.

- Digit Symbol Substitution Test: this test was used to assess visuomotor coordination, motor persistence, sustained attention, and response speed of the patients. The test consists of four rows, with each row containing 25 blank squares. Each square is randomly assigned a number from 1 to 9 . A key of symbols corresponding to each number is provided on the top of the sheet. Following a practice trial of seven squares, the patient is required to fill in the blank spaces with the corresponding symbol as quickly as possible. The Indian norms ${ }^{17}$ for the test were used.

- Trail Making Test ${ }^{18}$ : this test is a reliable measure of visual attention and task switching. The test can provide information regarding visual search speed, scanning, speed of processing, mental flexibility, and executive functioning.

- Stroop Test ${ }^{19}$ : this test measures the ease with which a perceptual set can be shifted both to conjoin demands and suppressing a habitual response in favor of an unusual one. In this test, the color names "blue," "green," "red," and "yellow" are printed in capital letters on a paper. The color of the print occasionally corresponds with the color designated by the word. The words are printed in 16 rows and 11 columns, and the patient is required to name the "color" rather than the print word. Test-retest reliability of the Stroop Test was assessed and the correlation of the Color-Word Scores from the first and second administration was 0.90 , suggesting a high degree of temporal stability.

- Psychological Well-Being Index ${ }^{20}$ : The Psychological General Well-Being Index is a measure of the level of subjective psychological well-being. It assesses self-representations of intrapersonal affective or emotional states reflecting a sense of subjective well-being or distress and thus captures what we could call a subjective perception of well-being. Consisting of 22 standardized items, the tool produces a single measure of psychological well-being under six subscale domains: anxiety, depression, positive well-being, self-control, general health, and vitality. Higher scores on the scale indicate a greater sense of well-being.

\section{Statistical Analysis}

In this study, all the scales were scored and quantitative analysis was performed through descriptive statistics. Student's $t$-test was used to differentiate between the groups. Pearson's correlation was used to correlate between variables. 


\section{Results}

Mean age of the participants in both groups was 52 years. Sexwise they were equally distributed in healthy controls, with a slightly higher representation of females in the diabetic group. Majority of the patients in both the groups were educated up to graduation level. In-service and homemakers constituted majority of the sample (-Tables $\mathbf{1}$ and $\mathbf{2}$ ).

The groups differed significantly in terms of processing speed and response inhibition, with healthy controls having better performance on the variables compared with patients with diabetes. No significant difference was found between the groups in domains of working memory and attention though.

Comparison of psychological well-being of the groups yielded expected results, with healthy controls having overall better psychological well-being compared with patients with diabetes. Domainwise, healthy individuals had lower subjective anxiety and depression levels compared with those with diabetes. Patients with diabetes had better self-control though. No difference was found in the domain of general health.

Duration of illness was further analyzed for relationship if any with cognitive functions and psychological well-being in patients with diabetes (-Table 3). Duration of illness was found to have a significantly negative relationship with response inhibition, indicating longer duration of illness to be related to poorer response inhibition. It was similarly related to processing speed and working memory functions in patients with diabetes.

In domains of psychological well-being, duration of illness was found to have a significant relationship with subjective anxiety symptoms. Relationship with other subdomains of psychological well-being was not significant.

\section{Discussion}

There was relatively a higher percentage of women with diabetes $(53 \%)$ compared with men $(47 \%)$ in the sample. Conventionally, men are likely to have a higher prevalence of diabetes type 2 compared with women. ${ }^{21}$ Other risk factors associated with diabetes were beyond the scope of this study and thus not explored.

The study findings suggest the healthy middle-aged controls had significantly better response inhibition and processing speed compared with patients with diabetes. This is in concurrence with the study by Ishizawa et $a l,{ }^{22}$ which also states that patients with type 2 diabetes show significantly decreased response inhibition. Patients with diabetes are known to have complexities in visuomotor coordination, motor persistence, sustained attention, and response speed. Visual-motor integration, which is related to executive function in activities of daily living, is demonstrated to be associated with diabetes in male older adults. ${ }^{23-25}$

The groups, however, did not differ in the domain of working memory. Available literature has studies with different

Table 1 Sociodemographic details of the sample

\begin{tabular}{|c|c|c|c|c|c|}
\hline & & \multicolumn{2}{|c|}{ With diabetes } & \multicolumn{2}{|c|}{ Healthy controls } \\
\hline \multirow{3}{*}{\multicolumn{2}{|c|}{ Age }} & Mean & SD & Mean & SD \\
\hline & & 52.76 & 7.19 & 52.07 & 6.9 \\
\hline & & $\mathrm{N}$ & Percent & $\mathrm{N}$ & Percent \\
\hline \multirow[t]{2}{*}{ Education } & Graduate & 19 & 63.33 & 22 & 73.3 \\
\hline & Postgraduate & 11 & 36.67 & 8 & 26.67 \\
\hline \multirow[t]{2}{*}{ Sex } & Male & 14 & 46.67 & 15 & 50 \\
\hline & Female & 16 & 53.33 & 15 & 50 \\
\hline \multirow[t]{3}{*}{ Occupation } & Business & 5 & 16.67 & 8 & 26.67 \\
\hline & Service & 12 & 40 & 10 & 33.33 \\
\hline & Homemaker & 13 & 43.33 & 12 & 40 \\
\hline
\end{tabular}

Table 2 Difference between the groups on cognitive functions

\begin{tabular}{|l|l|l|l|l|l|l|}
\hline \multirow{2}{*}{} & \multicolumn{2}{|c|}{ Healthy controls } & \multicolumn{2}{c|}{ With diabetes } & \multicolumn{2}{|c|}{} \\
\cline { 2 - 7 } & Mean & SD & Mean & SD & $t$-Value & $p$-Value \\
\hline Working memory (N back 1) & 8.22 & 1.251 & 7.69 & 1.644 & 1.324 & 0.191 \\
\hline Working memory (N back 2) & 6.33 & 2.019 & 5.77 & 1.773 & 1.079 & 0.564 \\
\hline Processing speed (DSST) (time) & $\mathbf{2 5 1 . 5 6}$ & $\mathbf{9 1 . 7 2 3}$ & $\mathbf{3 5 0}$ & $\mathbf{1 6 1 . 8 7 2}$ & $\mathbf{- 2 . 7 3 7 ^ { \mathrm { a } }}$ & $\mathbf{0 . 0 0 9}$ \\
\hline Attention (TMT 1) (time) & 64.59 & 25.938 & 63.88 & 21.161 & 0.109 & 0.914 \\
\hline Attention (TMT 2) (time) & 114.33 & 47.232 & 134.54 & 48.297 & 1.540 & 0.130 \\
\hline Response inhibition (Stroop effect) & $\mathbf{1 0 7 . 6 7}$ & $\mathbf{6 . 1 7 1}$ & $\mathbf{9 9 . 5 0}$ & $\mathbf{1 6 . 3 8 4}$ & $\mathbf{2 . 4 1 9}^{\mathrm{b}}$ & $\mathbf{0 . 0 1 9}$ \\
\hline
\end{tabular}

Abbreviations: DSST, Digit Symbol Substitution Test; SD, standard deviation; TMT, Trail Making Test. ${ }^{\mathrm{a}} p<0.01$ level. ${ }^{\mathrm{b}} p<0.05$ level. 
opinions on memory functions in diabetes, with some suggesting a significant difference in memory functions in healthy individuals compared with individuals with diabetes $^{26}$ and some suggesting no significant difference. ${ }^{27}$ The difference though could be due to different methodology adopted by the studies.

Psychological well-being is a unique construct where quantification may vary depending on subjective or objective perception. The assessment of well-being in this study was subjective and based on a Psychological Well-Being Index, a self-rated scale, and the results (-Table 4 ) suggest that middle-aged adults with diabetes had poor psychological well-being in domains of subjective anxiety and depression compared with healthy controls. This is in concurrence with existing literature. It is suggested that due to poor glycemic control complications in diabetes, anxiety symptoms are very prominent in patients with diabetes. ${ }^{28}$ Similarly, psychological burden of the illness, hypothalamic-pituitaryadrenal axis activation, sleep disturbance, inactive lifestyle,

Table 3 Relationship between cognitive functioning and psychological well-being with duration of illness in subjects with diabetes

\begin{tabular}{|l|l|l|}
\hline \multirow{2}{*}{ Cognitive functions } & \multicolumn{2}{|c|}{ Duration of illness } \\
\cline { 2 - 3 } & $\boldsymbol{p}$-Value & Significance \\
\hline Response inhibition (Stroop effect) & $-\mathbf{0 . 6 9 5}^{\mathrm{a}}$ & $\mathbf{0 . 0 0 0}$ \\
\hline Working memory (N back 1) & -0.130 & 0.494 \\
\hline Working memory (N back 2) & $-\mathbf{0 . 5 0 3}^{\mathrm{a}}$ & $\mathbf{0 . 0 0 5}$ \\
\hline Attention (TMT 1) (time) & 0.254 & 0.175 \\
\hline Attention (TMT 2) (time) & 0.344 & 0.063 \\
\hline Processing speed (DSST) (time) & $-\mathbf{0 . 4 1 5}^{\mathrm{b}}$ & $\mathbf{0 . 0 2 2}$ \\
\hline Processing speed (DSST) (error) & 0.210 & 0.264 \\
\hline Psychological well-being & \multicolumn{2}{|l}{} \\
\hline Positive well-being & -0.146 & 0.442 \\
\hline Self-control & 0.089 & 0.64 \\
\hline Anxiety & $\mathbf{0 . 3 6 1 ^ { \mathrm { b } }}$ & $\mathbf{0 . 0 5 0}$ \\
\hline Depression & -0.055 & 0.773 \\
\hline Vitality & 0.122 & 0.521 \\
\hline General health & -0.063 & 0.742 \\
\hline
\end{tabular}

Abbreviations: DSST, Digit Symbol Substitution Test; SD, standard deviation; TMT, Trail Making Test.

${ }^{\text {a }} p<0.01$ level.

${ }^{\mathrm{b}} \mathrm{p}<0.05$ level. poor dietary habits, and environmental and cultural risk factors can lead to depressive symptoms in patients with diabetes. ${ }^{29}$ The finding was shared with the consulting team of the patients for further psychological intervention. However, the results also suggest a significant difference between the groups of self-control and vitality domains of the psychological well-being. Adults with diabetes were found to have higher self-control and vitality. This is in contrast to previous studies, ${ }^{30}$ which suggest that positive well-being, such as optimism, self-control, vitality, positive affect, and gratitude, are low in patients with diabetes than normal controls.

Vitality includes spiritedness, energy, and the state of being strong and active, which was relatively less in healthy individuals. It is expected that the psychological well-being of any individual with some morbid condition could be lower than disease-free healthy individuals. However, the nature of illness may have a bearing on the subjective well-being perception as well as resilience and coping of the individuals. It might be a possibility that adults with diabetes engaged in a more structured and prescribed health routine as they were under treatment and thus the possible reason of the finding.

Furthermore, a long duration of diabetes was found to have a significantly negative impact on response inhibition, processing speed, and working memory of middle-aged adults with diabetes (-Table 3). Prior researches revealed that working memory, psychomotor and motor integration, and inhibitory control are also very susceptible to the long-term effects of hypoglycemia or diabetes mellitus. ${ }^{31}$

Duration of illness was related only to the anxiety domain of psychological well-being in the patient sample. People with diabetes have a greater likelihood of developing mental health problems such as anxiety. It is possible that biological changes induced by diabetes alongside lifestyle limitations and feelings related to living with a serious chronic illness could all be linked with anxiety symptoms. ${ }^{32}$

It could be concluded that middle-aged adults with diabetes significantly differ than healthy individuals in cognitive functions of response inhibition and processing speed. No difference was found in working memory and attention though. Psychological well-being in middle-aged adults with diabetes was lower in terms of subjective anxiety and depression only. Adults with diabetes were found to have better self-control in the study. Overall, the presence of chronic illness such as diabetes has a detrimental impact on

Table 4 Difference between the groups on psychological well-being

\begin{tabular}{|c|c|c|c|c|c|}
\hline \multirow[t]{2}{*}{ Domains } & \multicolumn{2}{|c|}{ Healthy controls } & \multicolumn{2}{|c|}{ With diabetes } & \multirow[t]{2}{*}{$t$-Value } \\
\hline & Mean & SD & Mean & SD & \\
\hline Positive well-being & 10.11 & 1.867 & 10.35 & 2.607 & -0.378 \\
\hline Self-control & 10.78 & 2.172 & 8.54 & 2.121 & $3.796^{a}$ \\
\hline Anxiety & 8.48 & 3.837 & 14.77 & 4.590 & $-5.419^{a}$ \\
\hline Depression & 5.63 & 2.420 & 9.27 & 2.765 & $-5.105^{a}$ \\
\hline Vitality & 12.26 & 1.318 & 9.62 & 2.021 & $5.661^{\mathrm{a}}$ \\
\hline General health & 8.89 & 2.486 & 9.08 & 1.719 & -0.319 \\
\hline
\end{tabular}

Abbreviation: SD, standard deviation.

${ }^{a} p<0.01$ level. ${ }^{b} p<0.05$ level. 
patients' cognitive functioning and psychological well-being in general. The implications of the study lies in the understanding of cognitive functioning of the middle-aged patients and how it differs from healthy controls and possible inclusion of appropriate cognitive rehabilitation programs and psychotherapeutic interventions for the affected domains.

\section{Conflict of Interest}

None declared.

\section{References}

1 American Diabetes Association. Diagnosis and classification of diabetes mellitus. Diabetes Care 2009;32(Suppl 1) :S62-S67

2 Snoek FJ, Pouwer F, Welch GW, Polonsky WH. Diabetes-related emotional distress in Dutch and U.S. diabetic patients: cross-cultural validity of the problem areas in diabetes scale. Diabetes Care 2000;23(9):1305-1309

3 Shepard JA, Vajda K, Nyer M, Clarke W, Gonder-Frederick L. Understanding the construct of fear of hypoglycemia in pediatric type 1 diabetes. J Pediatr Psychol 2014;39(10):1115-1125

4 Cemeroglu AP, Can A, Davis AT, et al. Fear of needles in children with T1D mellitus on multiple daily injections (MDI) and continuous subcutaneous insulin infusion (CSII) Endocr Pract 2015;21:46-53

5 Balhara YP. Diabetes and psychiatric disorders. Indian J Endocrinol Metab 2011;15(4):274-283

6 Moheet A, Mangia S, Seaquist ER. Impact of diabetes on cognitive function and brain structure. Ann N Y Acad Sci 2015; 1353:60-71

7 Ohmann S, Popow C, Rami B, et al. Cognitive functions and glycemic control in children and adolescents with type 1 diabetes. Psychol Med 2010;40(1):95-103

8 Li W, Huang E, Gao S. Type 1 diabetes mellitus and cognitive impairments: a systematic review. J Alzheimers Dis 2017;57(1):29-36

9 Tonoli C, Heyman E, Roelands B, et al. Type 1 diabetes-associated cognitive decline: a meta-analysis and update of the current literature. J Diabetes 2014;6(6):499-513

10 Gregg EW, Yaffe K, Cauley JA, et al. Is diabetes associated with cognitive impairment and cognitive decline among older women? Study of Osteoporotic Fractures Research Group. Arch Intern Med 2000;160(2):174-180

11 Munshi M, Grande L, Hayes M, et al. Cognitive dysfunction is associated with poor diabetes control in older adults. Diabetes Care 2006;29(8):1794-1799

12 Fontbonne A, Berr C, Ducimetière P, Alpérovitch A. Changes in cognitive abilities over a 4-year period are unfavorably affected in elderly diabetic subjects: results of the Epidemiology of Vascular Aging Study. Diabetes Care 2001;24(2):366-370

13 Hamed SA, Youssef A, Elserogy Y, et al. Cognitive function in patients with type 2 diabetes mellitus: relationship to stress hormone (cortisol) J Neurol Neurosci 2013;4:3

14 Hazari MAH, Reddy BR, Uzma N, Kumar BS. Cognitive impairment in type 2 diabetes mellitus. Int J Diabetes Mellit 2015;3(1):19-24

15 Kalar MU, Mujeeb E, Pervez S, et al. Assessment of cognitive status in type 2 diabetes. Int J Collab Res Intern Med Public Health 2014;6(8):235
16 Halder S, Mahato AK, Cognition in ageing: implications for assessment and intervention. In: Handbook of Research on Geriatric Health, Treatment, and Care. Hershey, PA: IGI Global; 2018: 118-133

17 Rao SL, Subbakrishna DK, Gopukumar K, NIMHANS Neuropsychological Battery-Manual. Bangalore, India: National Institute of Mental Health and Neurosciences; 2004

18 Lezak MD, Trail making test. In: Neuropsychological Assessment. 3rd ed. New York, NY: Oxford University Press; 1995

19 Trenerry MR, Crosson B, DeBoe J, Leber WR, Stroop Neuropsychological Screening Test Manual. Lutz, FL: Psychological Assessment Resources; 1989

20 Dupuy HJ. The Psychological General Well-Being Index (PGWB). Available at: https://eprovide.mapi-trust.org/instruments/ psychological-general-well-being-index.

21 Anjana RM, Pradeepa R, Deepa M, et al; ICMR-INDIAB Collaborative Study Group. Prevalence of diabetes and prediabetes (impaired fasting glucose and/or impaired glucose tolerance) in urban and rural India: phase I results of the Indian Council of Medical Research-INdia DIABetes (ICMR-INDIAB) study. Diabetologia 2011;54(12):3022-3027

22 Ishizawa KT, Kumano H, Sato A, Sakura H, Iwamoto Y. Decreased response inhibition in middle-aged male patients with type 2 diabetes. Biopsychosoc Med 2010;4(1):1

23 Yun HS, Kim MA, Kim MH, Suh SR, Kim H. Evaluation of visual-motor integration in elderly patient with diabetes mellitus. Hanguk Nonyonhak 2011;31:641-652

24 Dik MG, Jonker C, Comijs HC, et al. Contribution of metabolic syndrome components to cognition in older individuals. Diabetes Care 2007;30(10):2655-2660

25 Okereke OI, Kang JH, Cook NR, et al. Type 2 diabetes mellitus and cognitive decline in two large cohorts of community-dwelling older adults. J Am Geriatr Soc 2008; 56(6):1028-1036

26 Ruis C, Biessels GJ, Gorter KJ. van den Donk M, Kappelle LJ, Rutten GE. Cognition in the early stage of type 2 diabetes. Diabetes Care 2009;32(7):1261-1265

27 Spauwen PJJ, Köhler S, Verhey FRJ, Stehouwer CDA, van Boxtel MPJ. Effects of type 2 diabetes on 12-year cognitive change: results from the Maastricht Aging Study. Diabetes Care 2013;36(6):1554-1561

28 Berlin I, Bisserbe JC, Eiber R, et al. Phobic symptoms, particularly the fear of blood and injury, are associated with poor glycemic control in type I diabetic adults. Diabetes Care 1997;20(2):176-178

29 Holt RI, de Groot M, Golden SH. Diabetes and depression. Curr Diab Rep 2014;14(6):491

30 Ryff CD, Dienberg Love G, Urry HL, et al. Psychological well-being and ill-being: do they have distinct or mirrored biological correlates? Psychother Psychosom 2006; 75(2):85-95

31 Sommerfield AJ, Deary IJ, McAulay V, Frier BM. Short-term, delayed, and working memory are impaired during hypoglycemia in individuals with type 1 diabetes. Diabetes Care 2003;26(2):390-396

32 Katon WJ. Epidemiology and treatment of depression in patients with chronic medical illness. Dialogues Clin Neurosci 2011;13(1):7-23 